\title{
ELECTRONIC DISPATCH OF ENERGY CONSUMPTION IN A BUILDING WITH ITS OWN RENEWABLE ENERGY - SMART HOUSE
}

\author{
SERGEI SHCHEKLEIN ${ }^{1}$, OLEG TASHLYKOV ${ }^{1} \&$ ALEXEY TASHLYKOV $^{2}$ \\ ${ }^{1}$ Ural Federal University, Russia \\ ${ }^{2}$ LLC “OKO”, Russia
}

\begin{abstract}
In this study, it has been discussed methodically the control system of energy consumption from the power grid, generating electric energy on a seasonal basis (winter) heat load (thermocouples) and the utility of a set of renewable energy (solar photovoltaic, wind turbines and ground source heat pumps). It has also been taken into account the significant difference of energy network day and night consumption tariffs, seasonal heating load changes, solar insolation, and wind speeds. It has been figured out that the combined system of power supply at home, using the possibilities of the power system for the accumulation of excess renewable energy sources during the summer months, we can substantially simplify and reduce the cost of energy. The ability to use modern energy-saving equipment to simplify and reduce the consumer source system has been demonstrated. As well the new criteria for system optimization based on value analysis, the algorithm of complex consumer source control to implement a minimum cost supply at home, developed implementation flowchart of this algorithm based on modern microprocessor technology have been pointed out.

Keywords: renewable energy, solar photovoltaic, solar collectors, heat pumps, net zero energy building, wind turbines.
\end{abstract}

\section{INTRODUCTION}

Access to sustainable sources of energy is a key to sustainable development of mankind. Sustainability of economic development in the world is largely dependent upon the availability of energy sources. A $10 \%$ increase over the critical share of expenditures for the primary energy sources in the world gross product leads to global economic crises, like those of 1980 and 2008.

The rise in global energy consumption due to population growth and rising standards of living lead to deficiency in fossil fuel resources. Therefore, prices for fuel and electricity rise [1].

In 2015, installed capacity of all power plants in the world was approximately $5000 \mathrm{GW}$. The bulk of consumed energy is generated at thermal power plants that run on fossil fuel. This results in rapid depletion of natural resources and progressive pollution of the environment. The total capacity of all nuclear power plants (NPP) in the world is about 400 GW. Contribution of renewable energy sources (RES) to electric power generation is about $23 \%$.

In 2015, installed capacity of all wind power plants (WPP) in the world exceeded that of nuclear power plants; however, NPPs generate $60 \%$ more energy. Nuclear power plants emit almost no air pollutants during their operation. Hydroelectric power plants (HEPP), NPPs, and wind power plants have the lowest $\mathrm{CO}_{2}$ emission rates (when emissions over the entire energy life cycle are considered).

According to the Intergovernmental Panel on Climate Change (IPCC), nuclear power has the strongest potential to mitigate the negative effects of various power generation technologies and the lowest average costs in the energy sector [2]. A unique feature of nuclear power is reproduction of nuclear fuel. Fast reactors can produce more nuclear fuel than they 
consume (expanded reproduction of nuclear fuel), help solve the problem of accumulation of spent nuclear fuel and minimize the amount of radioactive waste [3].

Together with the increase of energy production rates, the following two tasks need to be solved:

1. Increase the efficiency of primary energy (non-renewable and renewable sources) conversion into the kinds of energy (thermal, mechanical, electrical) consumed by people;

2. Increase the efficiency of energy use by consumers (industries and population).

The presented report deals with separate issues related to the problem of increasing the efficient usage of energy from various sources in the energy-efficient houses.

\section{ENERGY-EFFICIENT HOUSE}

The term "net zero energy building" is widely used in the modern international community and has an ambiguous interpretation. To reach a "zero" energy balance, one should first reduce the consumption by means of architectural and engineering solutions (orientation and shape of the building, daylight illumination, natural ventilation, evaporative cooling, etc.).

Concept of net zero energy building assumes that a building can satisfy all its energy needs through the use of inexpensive, available, green, and renewable energy sources. Moreover, the total amount of renewable energy generated on the site should be equal to or higher than the annual energy consumption of the building.

If the amount of self-generated energy cannot cover the amount of energy consumed by the building at some time, then traditional energy sources (electricity and natural gas) are used. Excess electricity (when self-generation exceeds the needs of a building) is either exported to the external power grid or stored locally.

For a net zero energy building, various renewable energy sources (solar batteries, solar water heating, wind energy, hydropower, and biofuel) are used, and are preferred over the traditional energy sources (Fig. 1). At the same time, renewable energy sources can be located both inside the building and on the adjacent land for example solar panels and solar water heating systems located on the roof of a building and solar or wind power plants located on the lands adjacent to the building.

There are several types of buildings with zero net energy consumption. In four of them, a building is connected to an external power grid and uses "green" energy from various renewable energy sources, while in the fifth version a building operates independently from the external power grid [4].

There are a large number of various renewable energy sources and technologies for their conversion into useful kinds of energy. In theory, power supply of any consumer in any geographic location can be provided using renewable energy sources. The main question is what technologies to use and how much will it cost? Finding effective and economically achievable technical solutions (only renewable energy sources or their hybridization) is a complicated scientific and technical problem which calls for modern scientific and engineering approaches and solutions.

Therefore, we will consider ways to create an actual energy-efficient house with various degrees of approximation to the concept of a net zero energy building. At the same time, the main task will be to minimize the house owners' expenditures for electrical and thermal energy. 


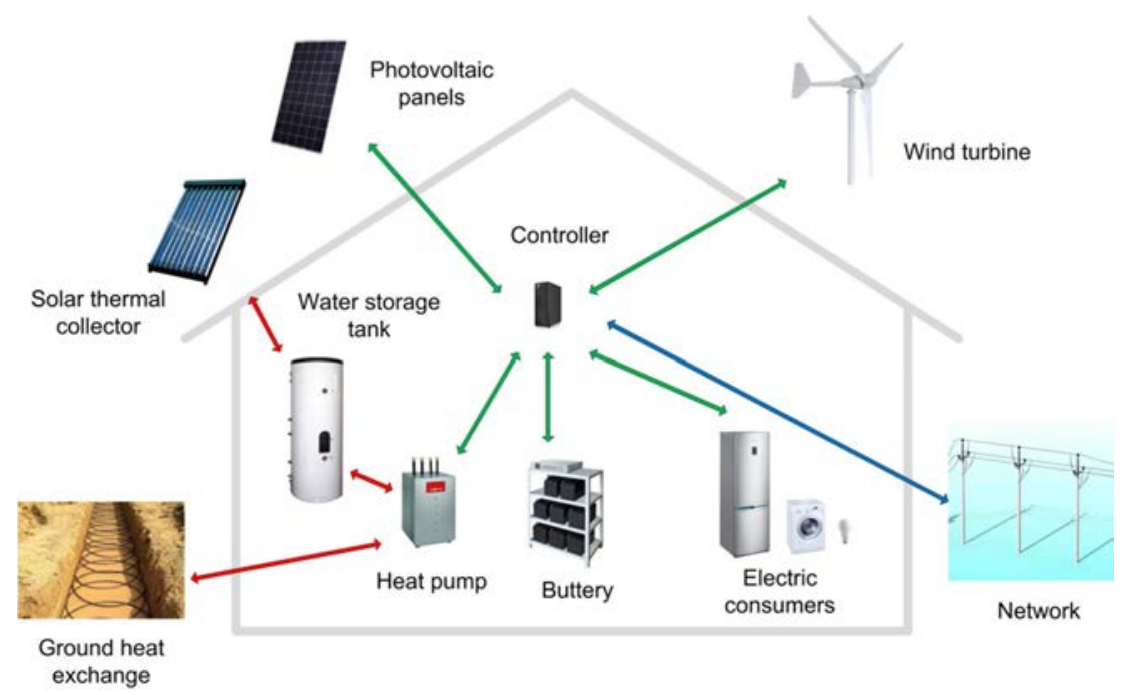

Figure 1: Schematic diagram of building energy supply.

To achieve the maximum energy efficiency of a building, it is necessary to:

- $\quad$ reduce heat losses;

- reduce the energy consumption;

- optimize the power supply system of a building;

- efficiently recover thermal energy from exhaust air, sewage system, etc. (recuperation);

- use renewable energy sources;

- implement automated monitoring and control systems.

Generation of energy from renewable sources located inside the building ensures the highest stability of a utility system operation. An energy-efficient house consumes less energy from the external electric and thermal energy providers, thus reducing the load on the power grid. In some cases, excess electric energy collected from renewable sources can be transferred to the power grid during peak hours. Being connected to the grid is cheaper and more convenient for the owners of such building than being autonomous, as in the latter case they will have to develop expensive technologies of energy storage by themselves.

\section{SUBJECT AND METHOD OF THE STUDIES}

As an example, let's consider a dwelling house (townhouse of 8 apartments) located $20 \mathrm{~km}$ from Yekaterinburg, a result of reconstruction of a cattle barn with small amount of initial investment. The purpose of reconstruction was to demonstrate and evaluate the possibilities of creating an energy-efficient house in the Ural region, to explore the possibilities of using various types of renewable energy sources for power supply, space heating, and to polish the methodology for optimizing the contributions of various renewable energy sources (by capacity and mode of operation during the day). 


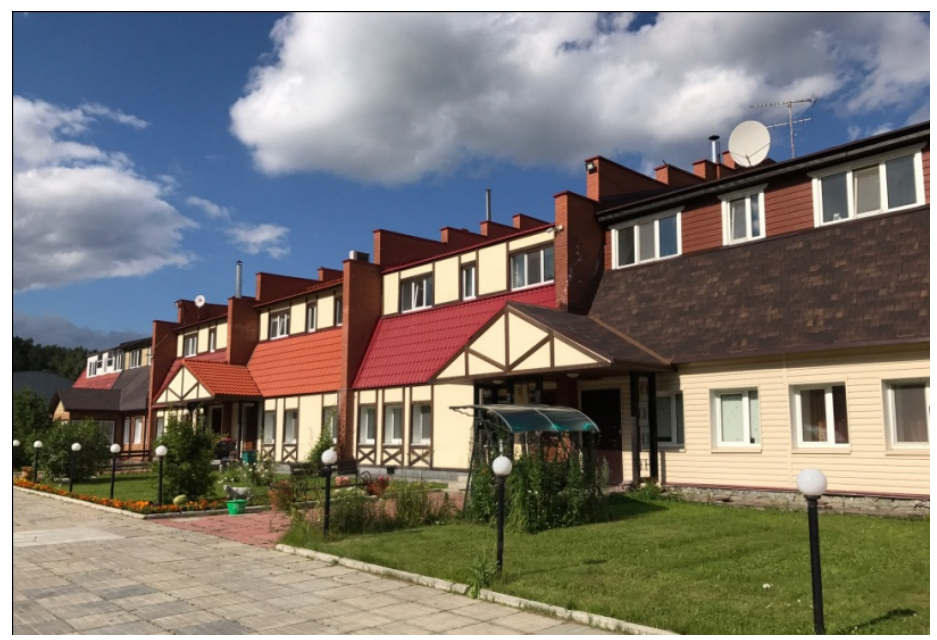

Figure 2: Townhouse of 8 apartments.

The building has high characteristics of thermal insulation, comfort, external power and a gas supply system, heat supply, and sewerage. Photovoltaic panels, solar collectors, wind turbines, and a heat pump plant are used as renewable energy sources (Fig. 2).

\subsection{Electricity}

The main source of electric power is a local $10 \mathrm{kV}$ grid. One of the main tasks is to minimize the energy consumption from the grid (maximize consumption from renewable energy sources. The building uses solar panels for a standby power supply (Fig. 3). Also, wind power plants with a total capacity of $600 \mathrm{~W}$ were installed near the house.

\subsection{Solar panels}

The building uses solar panels for a standby power supply. Solar panels with a rated voltage of $12 \mathrm{~V}$ and a total capacity of $800 \mathrm{~W}$ were installed on the façade along with battery charging controllers. The house has an additional $12 \mathrm{~V}$ wiring circuit. Altogether, the house has two voltages: 12 and $220 \mathrm{~V}$ (from the external power grid).

The task of organizing the operation of solar batteries in parallel with the power grid is currently being solved. Solar panels generate electric energy of $220 \mathrm{~V}$ to supply apartments, and any excess energy is transferred to the grid.

In the summer months, the energy generated by solar panels during the daylight hours completely supplies the needs of house consumers, and sometimes exceeds them. The excess electricity is supplied to the power grid (in 2016,300 kWh were supplied to the grid) free of charge, since Russia does not yet have a law regulating the sale of electric energy coming from microgeneration. The advantage of this solution is the absence of an expensive energy storage system. In this case, power grid is used as a storage cell of unlimited capacity. In spring and summer, when solar energy is in excess, the generated energy is supplied to the grid, and in winter this energy can be taken away owing to the ability of the grid to receive an unlimited amount of energy. This requires a bi-directional electric meter to measure the amount of energy given and taken (Figs 4 and 5). 


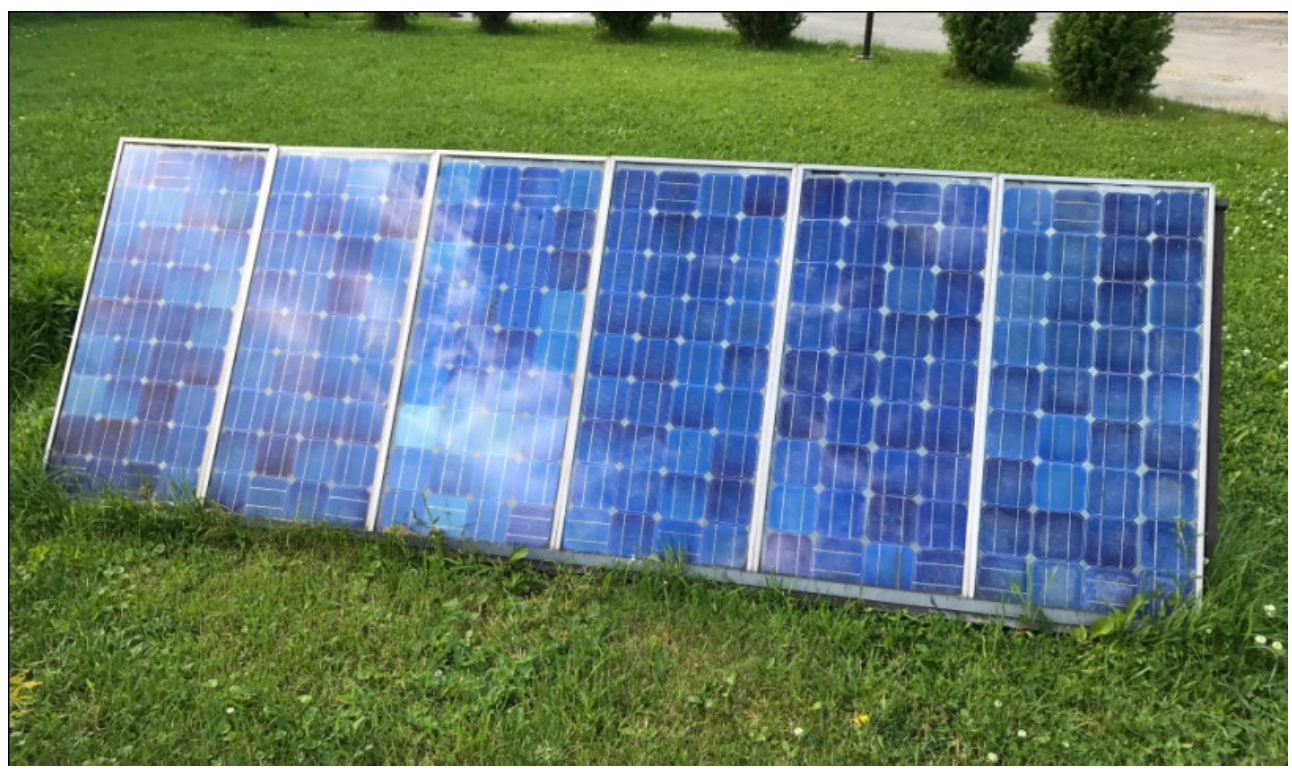

Figure 3: Solar panels.

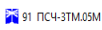

Bepcrn Konфunураттра or 27.12:16

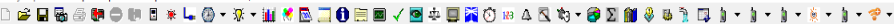

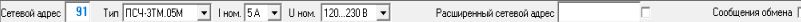

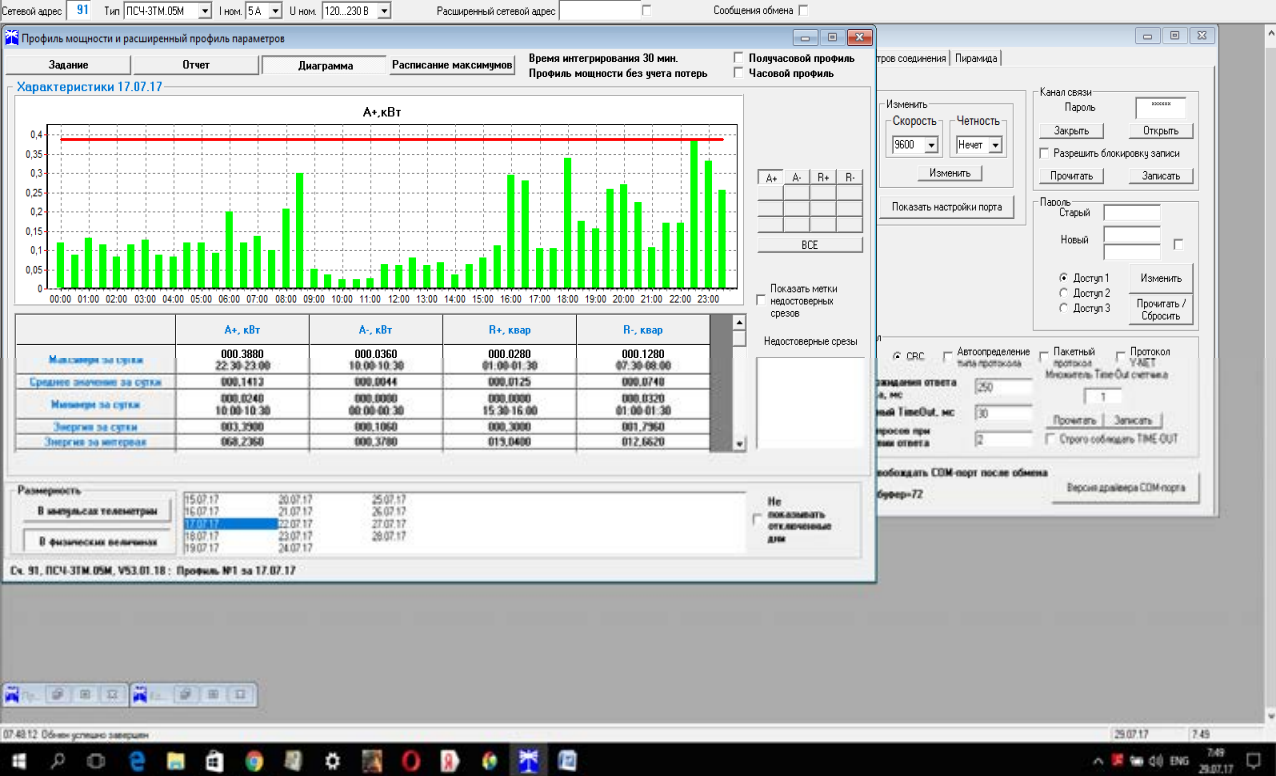

Figure 4: Energy consumption from the power grid. 


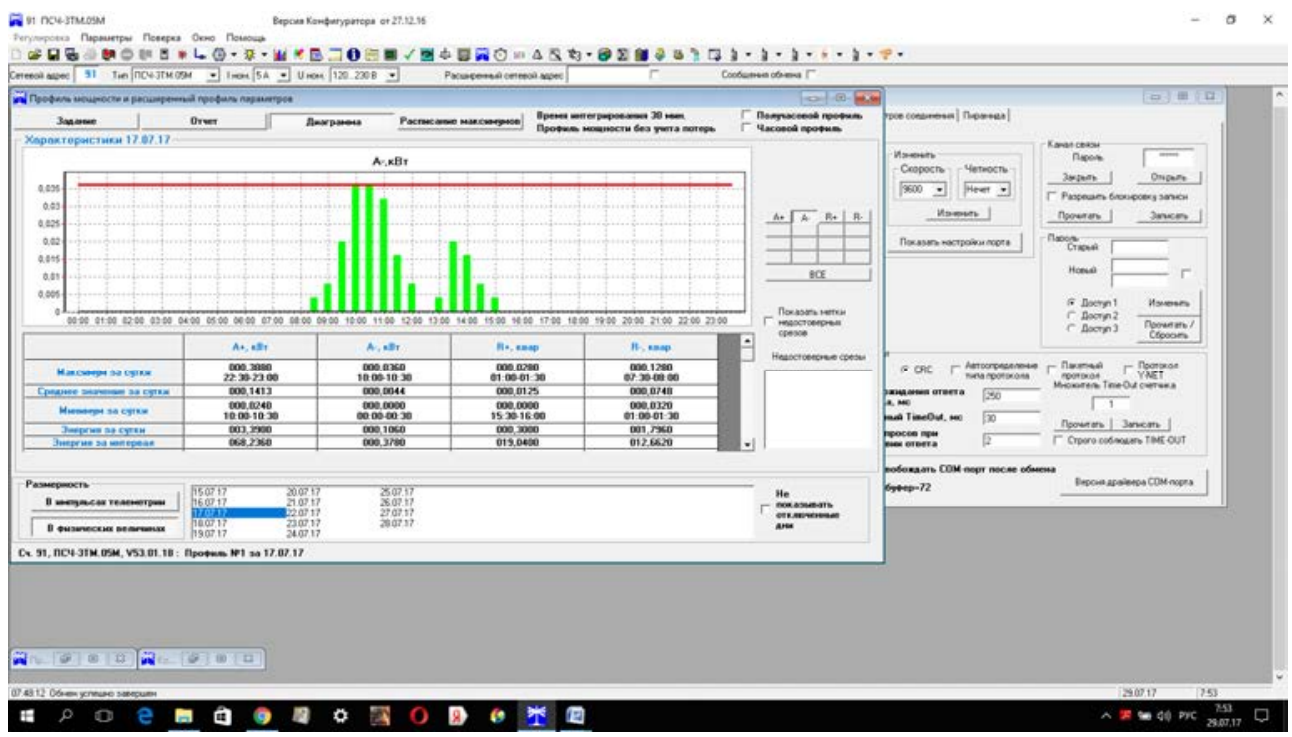

Figure 5: (Excess) energy transmission to the power grid.

Russia is currently drafting a law on microgeneration (installations up to $15 \mathrm{~kW}$ with any operating principle based on the use of renewable energy sources) that would permit connection to power grids upon notification. After the purchase of a power plant and its registration, a bi-directional electric is installed. Energy provider enters into contract with the owner of the plant on the procedure for the settlement of accounts. This will give a powerful impulse to the development of renewable energy sources in Russia. Plants will become cheaper, as expensive storage cells will no longer be necessary.

\subsection{Heat supply}

\subsubsection{Solar collectors}

In 2000-2009, various designs of water heating solar collectors manufactured in Russia and abroad were tested. As a result, an optimal collector design was developed, its weaknesses eliminated. Since 2010, water for the house in summer period (from March to October) has been heated using solar collectors only. Operating principle of the existing water heating system is as follows: in a large storage tank of about 250 liters a predetermined temperature of about $70^{\circ} \mathrm{C}$ is maintained. Water temperature in the tank should be at least $60^{\circ} \mathrm{C}$ to prevent the appearance of the pathogenic bacteria - Legionella.

\subsubsection{Heat pump installation}

The house is heated using a heat pump system. The energy powering the heat pump compressor drive is taken from the external power grid. Soil is used as a source of low-grade heat (average annual temperature of soil is $6-7^{\circ} \mathrm{C}$ ). For the heat exchanger, a 100 meter deep well was drilled. The heat pump raises the heat carrier temperature from $7^{\circ} \mathrm{C}$ to the required level $\left(30-35^{\circ} \mathrm{C}\right.$ for air heating using fan coil units).

In the hot summer months, the compressor is shut down, and a small pump (20 W) starts to slowly circulate the heat carrier between the fan coil units and the soil: the fan belonging to the fan coil unit supplies cold air $\left(16^{\circ} \mathrm{C}\right)$ to the room, and the heat pump works as an air 
conditioner. The soil is heated in the process. Thermal energy stored in the soil during the summer increases the heating efficiency of the plant in winter.

\subsection{Experimental study}

Series-connected photovoltaic modules with peak capacity of $180 \mathrm{~W}$ each (3 panels) connected to a grid tie inverter are the main components of the plant. The modules always face south and are installed vertically.

The second element of the system is the StecaGrid 500 grid tie inverter designed for installation in solar photovoltaic systems operating in parallel with the centralized power grid. The inverter converts the direct current received from solar modules into alternating current, has a maximum power point tracking system, and synchronizes the amplitude, frequency, and phase of the output voltage with those of the mains. In case of a power failure, the inverter will stop supplying power to the grid for safety reasons.

With a bi-directional electric meter used to measure the amount of energy transferred to the grid it is also possible to estimate the amount of energy taken from the grid (when load is present). The meter is designed to account for active and reactive power in direct and reverse directions in single-phase AC grids with a frequency of $50 \mathrm{~Hz}$. The meter has a computer interface and can be used together with a data logger [5].

The studies were performed using a special measuring complex developed by the UrFU together with the National Instruments Corporation to record the following climatic and energy characteristics:

- ambient temperature,

- arrivals of direct and diffuse solar radiation,

- $\quad$ occurrence and intensity of precipitation (rain, snow),

- inverter input voltage and amperage in the AC circuit of the solar module array,

- inverter output voltage and amperage in the AC circuit,

- electric energy transferred to the power grid by the inverter,

- electric energy received from the power grid by the inverter.

The obtained data make it possible to estimate the theoretical annual installed capacity utilization factor of the on-grid photovoltaic station as the ratio of the energy generated by the photovoltaic power plant over a year to the potential amount of energy under continuous operation at the rated (peak) capacity.

Note that own power consumption of the grid tie inverter $(0.5 \mathrm{~W})$ and a minimum level of capacity necessary to start synchronization with the grid $(2 \mathrm{~W})$ reduce the daily output by 25-30 Wh and represent the auxiliaries of the on-grid photovoltaic station.

Actual energy production show results are slightly below theoretical levels (Fig. 6). The greatest match is the theoretical values of electricity production which is achieved in spring and summer. In spring to summer there are significant growth of Capacity utilization factor (day).

The summer and winter periods are characterized by a significant effect of a change in the position of the sun relative to the stationary oriented photovoltaic modules and significant fluctuations in the atmosphere transparency. The experimental data make it possible to estimate the (annual) installed capacity utilization factor of the photovoltaic station as $8 \%$. 


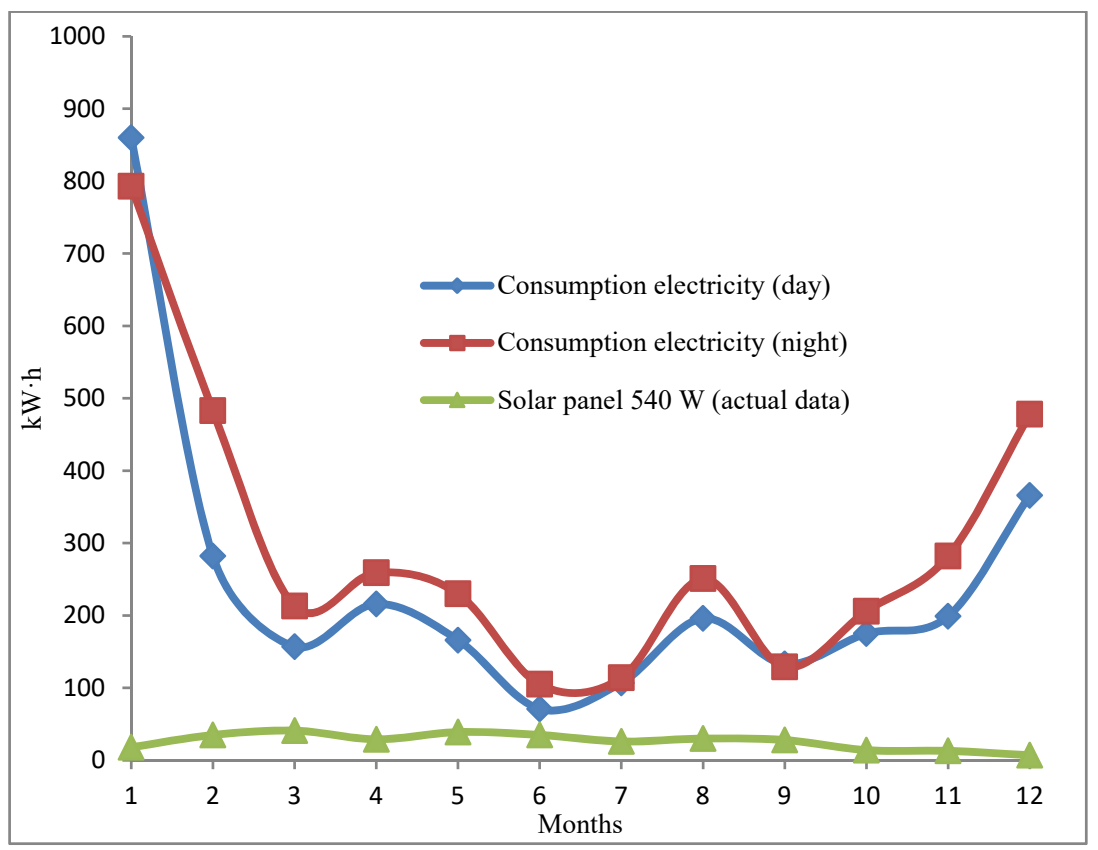

Figure 6: Graphs of electricity consumption and electricity generation solar panels.

In all seasons of a year, the electricity production rates are the highest around noon, and in the spring-and-summer periods the value of the (daily) installed capacity utilization factor reaches $57-62 \%$.

\section{RESULTS AND DISCUSSION}

By observing several conditions in the operation of the whole system, it is possible to use the house with minimum expenditures for power consumption from the grid and to gain maximum profit from selling the excess energy to the grid.

1. It is more favorable to operate the heat pump at night rate; in this case, the heat is utilized for space heating, and the excess is accumulated in the thermal energy storage.

2. The amount of heat accumulated in the thermal energy storage must be sufficient to heat the house in the daytime with a small margin. Accumulation of larger amount of heat is unpractical due to high losses during its storage.

3. It is more practical to accumulate excess electric energy generated by solar panels and WPPs in a battery for sale to the power grid at a day rate in case of a two-rate tariff and in "peak" hours in case of a three-rate tariff.

4. Accumulation of electric energy in a battery at the night rate and its transfer to the grid at the day rate.

5. It is necessary to have a power margin in the battery in case of a power grid failure.

6. Heating system can operate in the "standby" mode (temperature in the house reduced to $5^{\circ} \mathrm{C}$ ) to reduce the cost of heating in case of long-time absence of people in the house. 
To meet these conditions, the entire system needs automation to ensure its efficient operation, control and management, including remote control. The automation system should have the following functions:

1. Control of the heat pump depending on the time of day and heat requirement of the house.

2. Inverter control to transfer the electric energy accumulated in the battery to the grid at the day rate.

3. When the battery is fully charged, all excess energy should be transferred to the grid regardless of the time of day.

4. Keeping records of electric energy consumed, generated, and sold to the grid. History maintenance.

5. Local and remote control and monitoring of climate (temperature, humidity, ventilation) in the house.

6. Control of temperature and ventilation in the house depending on the time of day (day/night).

7. "Normal" and "standby" modes of operation of heating and ventilation system.

8. Possibility of system supervision.

9. Combination with security and fire alarm functions.

10. Remote control and monitoring using a mobile application on an Android and iOS (Apple) smartphone.

To implement the above functions, a system needs to have the following features:

1. Real-time clock with GSM network synchronization and correction of daily variation.

2. GSM modem for remote monitoring and control.

3. Ethernet connection for remote monitoring and control.

4. Memory cards of microSD type up to 4 GB for history maintenance.

5. A 1-wire interface for connecting up to 10 digital temperature sensors of DS18B20 type (measuring ranges from -55 to $+125^{\circ} \mathrm{C}$ ).

6. ADC for monitoring the output of solar cells and WPP.

7. ADC for battery voltage monitoring.

8. Relay outputs to control the heat pump and inverter.

9. Indications displaying the operating modes.

10. Fire and security alarm loops.

11. USB interface for the system monitoring and configuration.

12. Monitoring and control panel.

A microcontroller based device with ARM (Advanced RISC Machine) architecture is used as a climate management system in an energy-saving house. Microcontrollers with such architecture are characterized by low power consumption and, at the same time, have sufficient processing power to solve the automation tasks.

To control the heat pump, it is necessary to monitor the water temperature in the thermal energy storage, temperature in the house, outside temperature, and to control the time-of-day electricity tariffs. The amount of accumulated thermal energy can be calculated knowing the capacity of the thermal energy storage and its temperature. The value of the outside temperature can be used to calculate the heat losses of the house and the necessary amount of heat to be accumulated in the thermal energy storage for space heating at a day's rate. 


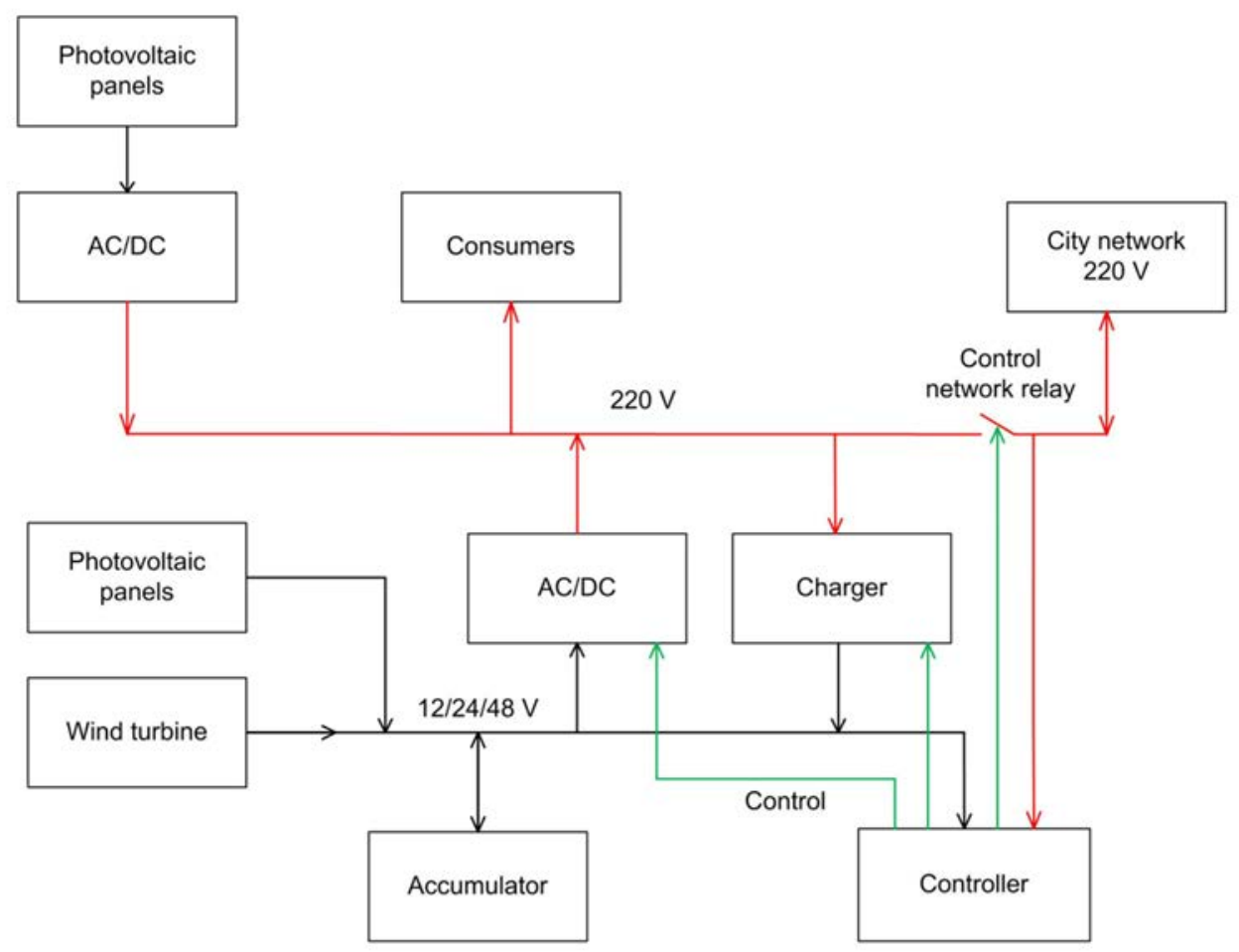

Figure 7: Control scheme of generation, consumption and sale of electricity to the grid.

The need for space heating at any given moment is determined by the temperature measured by the sensor in the house.

Data obtained from temperature sensors located in the thermal energy storage, in the house, and on the street, are used as input parameters. The heat pump is controlled by a solidstate relay. To control the system monitoring the process of battery charging from solar panels and WPP and to control the inverter converting the energy accumulated in the battery for its further sale, it is necessary to monitor the level of energy accumulated in the battery, i.e. battery voltage. The excess electricity is sold to the grid by turning on an inverter that converts the battery's DC voltage into 220 VAC with automatic phase and frequency synchronization. The time of switching the inverter on and off depends on the amount of energy stored in the battery, tariff rate, and on the presence or absence of voltage in the mains.

While selling electricity to the grid, note that there should always be some power left in the battery in the event of a possible grid failure. If there is no power supply from solar panels and WPP and no emergency energy margin in the battery, the battery should be charged to the emergency level from the grid.

\section{CONCLUSION}

There is a wide range of renewable energy sources and technologies for their conversion into useful kinds of energy.

In theory, power supply of any consumer in any geographic location can be provided using renewable energy sources. 
The search for optimal, economically, acceptable, technical solutions (only renewable energy sources or hybridization) is a complex scientific and technical problem requiring modern scientific and engineering approaches and solutions.

Due to the growing interest of consumers in the use of renewable energy sources, minimization of expenditures for power supply and space heating of a house receives priority. One of the ways to reduce the cost of energy consumption while using renewable energy sources is the ability to sell excess energy generated to an external power grid.

To minimize the cost of the house energy consumption, an electronic supervision system is needed. This system should control energy flows (battery charging, discharge of excess energy to the grid at a favorable rate, selection of the heating system operating mode, etc), monitor the performance of the house systems, that also include fire and security alarms.

\section{REFERENCES}

[1] Tashlykov, O., Shcheklein, S., Sesekin, A. Chentsov, A., Nosov, Y. \& Smyshlaeva, O., Ecological features of fast reactor nuclear power plants (NPPs) at all stages of their life cycle. WIT Transactions on Ecology and the Environment. 190(2), pp. 907-918, 2014.

[2] Nuclear energy's role in mitigating climate change and air pollution; Nuclear Power in the 21st Century. https://www.iaea.org/publications/magazines/bulletin/54-1. Accessed on: 21 Aug. 2017.

[3] Tashlykov, O., Shcheklein, S., Nosov, Y. \& Smyshlaeva, O., Ecological foresight in the nuclear power of XXI century. International journal of energy production and management, 1(2) pp. 133-140, 2016.

[4] On buildings with a "zero" energy balance and plans for "zeroing" abroad. Portalenergo. Effective energy saving. http://portal-energo.ru/articles/details/id/493. Accessed on: 17 Aug. 2017.

[5] Shcheklein, S.E., Matveev, A.V., Beloborodov, I.V., Nemikhin, Y.Ye. \& Vlasov, V.V., Study of Photovoltaic Grid-Connected Station Efficiency in the Annual Cycle. International Scientific Journal for Alternative Energy and Ecology, 11(12) (199-200) pp. 37-51, 2016.

[6] Shcheklein, S.E., Nemikhin, Y.E., Nevyantsev, S.V., Korzhavin, S.A., Postovalov, A.O., Nosov, D.A. \& Zagafuranova, Y.Z., Renewable energy-based plant remote monitoring complex using wi-fi channels and elements of artificial vision. WIT Transactions on Ecology and the Environment, 190(2), pp. 1185-1194, 2014. 